\title{
Impact of cosmogenic Ar-39 production on groundwater dating
}

\author{
S.MusY ${ }^{1}$, K. HINSBY ${ }^{2}$, J.SÜLTENFUSS ${ }^{3}$, J.LINDERBERG ${ }^{4}$ \\ R.PURTSCHERT ${ }^{1}$
}

${ }^{1}$ Climate and Environmental, University of Bern, 3012 Bern, Switzerland (*correspondence:

stephanie.musy@climate.unibe.ch) 2Geological Survey of

Denmark and Greenland, Øster Voldgade 10, 1350

Copenhagen, Denmark (khi@geus.dk)

${ }^{3}$ Umweltphysik, University Bremen, Otto Hahn Allee, 28355, Bremen, Germany (suelten@uni-bremen.de)

${ }^{4}$ VandCenter Syd as, Odense, Denmark (i1@,vandcenter.dk)

The constant activity of Argon-39 ( $\left.\mathrm{t}_{1 / 2}=269 \mathrm{yrs}\right)$ in the atmosphere $(100 \% \mathrm{mod})$ and its inertness in the subsurface makes it an ideal dating tracer on time scales from 50 to 1200 years. A potential limitation is the possibility of underground production by neutron activation of potassium. Over modern Ar-39 concentrations have for example been observed in Uand Th- rich deep crystalline rocks [1]. Cosmogenic neutrons in shallow depths have little impact if recharge is fast. However, unlike neutrons, muons reach deeper layers but their relevance for radioargon production via ${ }^{39} \mathrm{~K}\left(\mu, v_{\mu}\right){ }^{39} \mathrm{Ar}$ reactions was never considered so far.

We report on a large scale groundwater dating campaign in Funen (Denmark). In this area, over modern ${ }^{39} \mathrm{Ar}$ activities are observed in low $U$ formations at relatively shallow depths. This is likely the result of ${ }^{39} \mathrm{Ar}$ production by muon capture [2]. In the presentation, calculated production rates are compared with ${ }^{39} \mathrm{Ar}$ and ${ }^{37} \mathrm{Ar}$ measurements. Additionally, ${ }^{85} \mathrm{Kr},{ }^{222} \mathrm{Rn},{ }^{36} \mathrm{Cl}$ and ${ }^{3} \mathrm{H} /{ }^{3} \mathrm{He}$ data are used to constrain residence time and production mechanisms. By considering the ${ }^{39} \mathrm{Ar}$ production rate- and the water residence time as function of depth, the integrated impact of cosmogenic ${ }^{39} \mathrm{Ar}$ production is evaluated for specific recharge scenarios. The results of over $100{ }^{39} \mathrm{Ar}$ measurements are then used for a regional mapping of groundwater residence times in this area highly affected by pesticides and fertilizers.

[1] O. Srámek et al. 2017 [2] D.-M. Mei et al. 2010 